\title{
Preeclampsia management modalities and perinatal death: a retrospective study in Woldia general hospital
}

\author{
Kenean Getaneh Tlaye ${ }^{1 *}$, Melese Linger Endalfer ${ }^{1}$, Mesfin Wudu Kassaw ${ }^{1}$, Mussie Mulugeta Gebremedhin $^{2}$ and
} Yared Asmare Aynalem ${ }^{3}$

\begin{abstract}
Background: Hypertensive disorders of pregnancy are among the most common causes of perinatal death. The disorders are highly linked to multiple factors that make prediction and prevention challenging. Early diagnosis and proper management play a crucial role in the wellbeing and life of the women and her baby. In this study, we aimed to assess the association between different management options of preeclampsia and perinatal death at a public hospital in Ethiopia.

Methods: A document review was conducted on 241 preeclamptic patients' medical files who have been admitted and delivered in Woldia General Hospital from 2011 to 2016. The study was conducted from August 8 - September 10, 2017 in the aforementioned public hospital in Woldia town, Ethiopia. Associations were tested using Pearson chi squared test and binary logistic regression with a $p$-value $<0.05$ considered significant.

Result: In this study, nearly 20 every 100 neonates from preeclamptic women has been died and the figure was higher (76.59\% Vs 23.4\%) among neonates from severe preeclamptic women than mild preeclamptic women $(p=0.01)$. More than two thirds of the patients (69.3\%) received magnesium sulfate to prevent convulsion. Perinatal death among women with diastolic blood pressures greater than $110 \mathrm{mmHg}$ at admission was nearly 3 times (Adjusted Odds Ratio $(A O R)=2.824$; 95\% Confidence Interval $(\mathrm{Cl})(1.154-6.038)$ ) higher compared to women with diastolic blood pressures below $110 \mathrm{mmHg}$.

Conclusion: In the 5-year period, the magnitude of perinatal death among inpatient preeclamptic women was remarkably high and of which stillbirths exceeded pre-discharge early neonatal death. Utilization of magnesium sulfate tended to increase across years. Maternal diastolic blood pressure at admission was significantly associated with perinatal death.
\end{abstract}

Keywords: Preeclampsia, Perinatal death, Management modalities, Woldia

\section{Background}

According to the Ethiopian Demographic and Health Survey, perinatal mortality rate is calculated as the sum of stillbirths and early neonatal deaths divided by the total sum of births expressed per 1000 pregnancies that lasted seven or

\footnotetext{
* Correspondence: kenan34@wldu.edu.et

${ }^{1}$ College of Health Science, Woldia University, Woldia, Ethiopia

Full list of author information is available at the end of the article
}

more months [1]. Globally, nearly $16 \%$ of the estimated 2.6 million stillbirths annually occur in pregnancies complicated by pregnancy induced hypertension [2]. Hypertensive disorders of pregnancy (HDP) precede $10 \%$ of early neonatal deaths (8/1000 live births) [3] and a significant proportion of late neonatal deaths (3/1000 live births) [4]. Even though HDP by itself impact the fetus and its survival after

(c) The Author(s). 2020 Open Access This article is licensed under a Creative Commons Attribution 4.0 International License, which permits use, sharing, adaptation, distribution and reproduction in any medium or format, as long as you give appropriate credit to the original author(s) and the source, provide a link to the Creative Commons licence, and indicate if changes were made. The images or other third party material in this article are included in the article's Creative Commons licence, unless indicated otherwise in a credit line to the material. If material is not included in the article's Creative Commons licence and your intended use is not permitted by statutory regulation or exceeds the permitted use, you will need to obtain permission directly from the copyright holder. To view a copy of this licence, visit http://creativecommons.org/licenses/by/4.0/ The Creative Commons Public Domain Dedication waiver (http://creativecommons.org/publicdomain/zero/1.0/) applies to the data made available in this article, unless otherwise stated in a credit line to the data. 
delivery, the management modalities used have also been associated with perinatal death.

Studies have shown that nationwide preeclampsiarelated perinatal mortality was highly linked with the country's economic index i.e., figures from high wealth index countries were low and disproportionally high perinatal mortality were reported from low- and middleincome countries (LMIC). In general, rates ranged from $4.7 \%$ to as high as $41.6 \%$ [5-8]. Similarly, perinatal mortality among patients with eclampsia was also reported to be 5 to $11 \%$ in High income countries (HIC) where as it was as high as $40 \%$ in LMIC $[9,10]$. Two studies conducted in public hospitals in Ethiopia; namely Jimma University Specialized Hospital and Mettu Karl Referral Hospital; revealed perinatal mortality among preeclamptic women were $317 / 1000$ births and $120 / 1000$ respectively $[11,12]$.

A study showed that inadequate and delayed initiation of treatment and preterm deliveries among preeclamptic women was found to be associated with poor fetal outcome [13]. As variation is perceived among the course of management modalities used by different institutions, its impact on perinatal death should be explored especially in resource limited areas. Therefore, the aim of this study was to assess the perinatal death rate and its association between preeclampsia management modalities and perinatal outcome among women who gave birth at Woldia General Hospital from 2011 to 2016.

\section{Methods}

\section{Study setting, design and eligibility criteria}

The study was conducted from August 8 - September 10, 2017 at Woldia General Hospital, Woldia, Ethiopia. Woldia town is the main town of North Wollo Zone. This town is located in Amhara region at $520 \mathrm{~km}$ North of the capital, Addis Ababa. According to the local administration report in 2016, the town has total population of 75 , 446 of which 38,167 were males and 37,279 were females. Regarding the health care system, the town has one public hospital, two public health center and 12 private pharmacies and 5 medium level clinics. The hospital provides both inpatient and outpatient services. At the time of the study, the hospital had 120 beds and 328 employees and of them there were 20 doctors, 128 nurses and 21 midwifes. It has an obstetrics and gynecology department but until the data collection time, there wasn't separate room to admit patients with preeclampsia. A hospital-based retrospective cross-sectional study was implemented. All preeclamptic women who were admitted and gave birth at Woldia General Hospital from September 1, 2011- September 1, 2016 were included for the review. Perinatal outcome which was dichotomized as alive or dead was assessed for neonates delivered after 28 completed weeks and through their early neonatal period before discharge ( $\leq 7$ days). As the study was planned to assess the effect of different patterns of preeclampsia management on perinatal death, subjects' medical files documented with coincidental appearance for possible causes of perinatal death were excluded. This included maternal death on arrival, during admission and labor, and multiple delivery. In addition, grossly incomplete medical files; subjects with the initial diagnosis of preeclampsia in the first-time at the emergency department and immediately delivered were also excluded. The reason for the latter was the author's assumption that much of the inpatient management scheme that of interest for the present study would have missed and there might also be the probability of misdiagnosis. Figure 1 showed the schematic representation of sampling procedure and excluded cases from each departments (Fig. 1).

\section{Data collection tools and quality assurance}

The data were collected using a pre-tested check list which assessed socio-demographic variables, obstetrics history, signs and symptoms at presentation, laboratory results, and perinatal outcomes. The data were obtained from admission registration logbooks, medical and nursing care progress notes, delivery registration books, laboratory and drug prescriptions. The data collectors were trained a 2-days intensive training on how to review and extract the required information from the patients' chart. They were also monitored by supervisors daily. The tool was pretested at Lalibela General Hospital and an effort was made to validate patients' data from different folders and registration books.

\section{Study variables}

The study outcome variable was a perinatal outcome from preeclamptic women, which was dichotomized as alive and dead. The independent variables were, sociodemographic factors such as patients age and residence; obstetric related factors; gestational age (at admission and delivery), antenatal follow up for current pregnancy; current medical history (comorbidities); conditions at admission such as blood pressure measurement, level of proteinuria and signs and symptoms for end organ involvement, treatment modalities including; anti-hypertensive modalities, anti-convulsion modalities, mode of delivery; and other perinatal related factors such as intra-partum fetal heartbeat, APGAR score and birth weight.

\section{Operational and term definitions}

A patient medical file was documented as incomplete if it failed to mention perinatal outcome (as dead or alive), or if greater than $20 \%$ of the independent variables were missed. In this study, perinatal death included stillbirths (fetal death inside the uterus after 28 weeks) and early neonatal deaths (deaths within the first week after delivery). Gestational ages reported in the patient's file was 


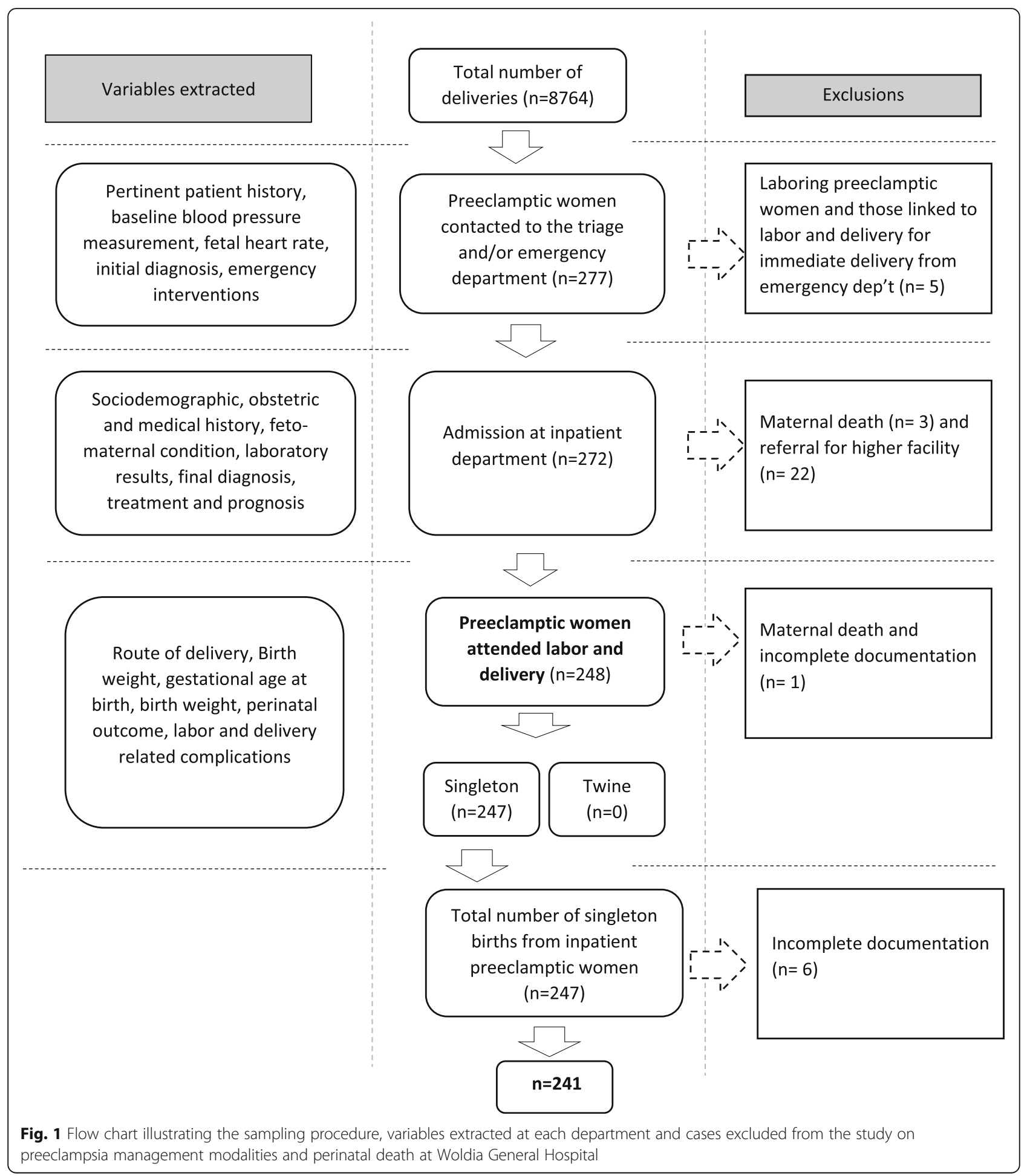

considered valid if it was calculated from the last normal menstrual period or using obstetric ultrasound. Fetal heart beat was usually obtained with Pinard fetoscope and a presence of any single value lower $100 \mathrm{bpm}$ or above $160 \mathrm{bpm}$, classified as abnormal pattern. We have used the routine clinical classification of preeclampsia as mild and severe. Hence, cases of documented blood pressure of more than $140 / 90 \mathrm{mmHg}$ but less than 160 $\mathrm{mmHg}$ systolic or $110 \mathrm{mmHg}$ diastolic with qualitative dipstick proteinuria less than +2 (mild proteinuria) was labeled as mild whereas a persistent systolic blood pressure of $>160 \mathrm{mmHg}$ or diastolic pressure of $>110$ 
$\mathrm{mmHg}$ with significant protein excretion of greater than +3 (marked proteinuria) or suggestive evidence for end organ involvement was recorded as severe preeclampsia. If preeclamptic women reported at least one of these symptoms; headache, visual problem, epigastric pain and placental abruption, platelet count below $100,000 / \mathrm{mm}^{3,}$ or aspartate aminotransaminase (AST) $>70 \mathrm{IU} / \mathrm{L}$, the subject was labeled as having signs of end-organ involvement. Comorbidity status for HIV, diabetes mellitus, chronic hypertension and anemia was assessed as either 'Yes/No' based on patient's self-report or laboratory result. Labor and early neonatal complications were assessed by a positive finding for at least one of the following complications: meconium aspiration, cord prolapse, vasa previa, prolonged labor (more than 24h.), uterine rupture, neonatal tetanus, severe jaundice, neonatal sepsis, life threatening congenital defect. Women with hemoglobin level less than $11 \mathrm{~g} / \mathrm{dl}$ was reported as anemic and classified as severe $(\mathrm{Hgb}<7.0 \mathrm{~g} / \mathrm{dl})$ moderate (Hgb 7.0-9.9 g/dl) and mild (Hgb 10.0-10.9 g/ dl). Time-lapse measurements were taken in hours and categorized based on their mean, median, or percentile after checking for their normality.

\section{Data processing and analysis}

Data were entered and analyzed by Statistical Package for the Social Science (SPSS) version 23 (RRID:SCR 002865). Percentage, rate, frequency distribution, measure of central tendency such as mean and median as well as measure of dispersion like interquartile range and standard deviation were used to describe different variables. Continuous variables such as time measurements were checked for their normality and reported using mean and standard deviation if normally distributed or median and interquartile range (IQR) if skewed. Pearson's $\chi^{2}$ test were used to examine association between selected variables. The effect of each variable on perinatal death was first tested by bivariable logistic regression. Confounding bias imposed by independent variables was further controlled by multivariable logistic regression. Association was considered significant when the $p$-value was less than 0.05 and adjusted odds ratio values were reported along with their $95 \%$ confidence interval. For a better calculation of the effect of preeclampsia and its management schemes on perinatal death, the study tried to assess the effect of other possible causes of perinatal death using the variable 'labor and early neonatal complication' and controlled with multivariable logistic regression.

\section{Result}

There were 8764 deliveries attended at Woldia General Hospital in the study period of which 248 were diagnosed as preeclamptic and gave birth in the hospital. Seven medical files were further excluded due to maternal death and
Table 1 Obstetric and medical condition of patients at the time of admission

\begin{tabular}{|c|c|}
\hline Obstetric and medical condition at Admission & mean (SD) \\
\hline $\begin{array}{l}\text { Gestational age during admission (in weeks days) } \\
(n=239)\end{array}$ & $37^{+6}\left( \pm 2^{+5}\right)$ \\
\hline Diastolic blood pressure at admission ( $\mathrm{mmHg}$ ) & $105.87( \pm 10.58)$ \\
\hline Obstetric and medical condition at Admission & n (\%) \\
\hline \multicolumn{2}{|l|}{ Gravidity } \\
\hline Primigravida & $138(57.3 \%)$ \\
\hline multigravida & $103(42.7 \%)$ \\
\hline \multicolumn{2}{|l|}{ Antenatal follow-up for current pregnancy } \\
\hline Yes & $168(69.7 \%)$ \\
\hline No & $73(30.3 \%)$ \\
\hline \multicolumn{2}{|l|}{$\operatorname{Comorbidities}^{\mathrm{a}}(n=98)$} \\
\hline Yes & $57(58.2 \%)$ \\
\hline No & $41(41.8 \%)$ \\
\hline \multicolumn{2}{|l|}{ Dipstick proteinuria $(n=223$ ) } \\
\hline Mild proteinuria & $148(66.4 \%)$ \\
\hline Marked proteinuria & $75(33.6 \%)$ \\
\hline \multicolumn{2}{|l|}{ Degree/type of preeclampsia diagnosed } \\
\hline Mild preeclampsia & $99(41.1 \%)$ \\
\hline Severe preeclampsia & 139 (57.7\%) \\
\hline $\begin{array}{l}\text { Preeclampsia superimposed on chronic } \\
\text { hypertension }\end{array}$ & $3(1.2 \%)$ \\
\hline \multicolumn{2}{|l|}{ Sign and symptom of end organ involvement } \\
\hline \multicolumn{2}{|l|}{ Headache $(n=228)$} \\
\hline Yes & $111(48.7 \%)$ \\
\hline No & $117(51.3 \%)$ \\
\hline \multicolumn{2}{|l|}{ Visual problem $(n=229)$} \\
\hline Yes & $30(13.1 \%)$ \\
\hline No & $199(86.9 \%)$ \\
\hline \multicolumn{2}{|l|}{ Epigastric pain $(n=213)$} \\
\hline Yes & $18(8.5 \%)$ \\
\hline No & 195 (91.5\%) \\
\hline \multicolumn{2}{|l|}{ Abruptio placenta $(n=117)$} \\
\hline \multicolumn{2}{|l|}{ Yes } \\
\hline No & 117 (100\%) \\
\hline \multicolumn{2}{|l|}{ Thrombocytopenia $(n=58)$} \\
\hline Yes & $3(5.2 \%)$ \\
\hline No & $55(94.8 \%)$ \\
\hline \multicolumn{2}{|l|}{ Elevated liver enzymes $(n=52)$} \\
\hline \multicolumn{2}{|l|}{ Yes } \\
\hline No & $52(100 \%)$ \\
\hline
\end{tabular}

incomplete documentation and therefore findings from this study were reported based on 241 reviewed medical documents. The mean maternal age in years $( \pm \mathrm{SD})$ was 
Table 2 Time duration (in hours) for the patients and health care professionals to start some management measures on preeclamptic women admitted at Woldia General Hospital

\begin{tabular}{ll}
\hline Time lapses & $\begin{array}{l}\text { median (interquartile range) } \\
\text { in hours }\end{array}$ \\
\hline $\begin{array}{l}\text { Time lapsed from onset of current } \\
\text { symptoms to reach hospital }(n=236)\end{array}$ & $14(6.25-24)$ \\
$\begin{array}{l}\text { Time lapsed from admission to } \\
\text { beginning of MgSO4 }\end{array}$ & $1(0.5-1)$ \\
$\begin{array}{l}\text { Time lapsed from admission to } \\
\text { beginning of antihypertensive } \\
\text { medication }\end{array}$ ( $\left.n=101\right)$ & $0.5(0.28-1)$ \\
$\begin{array}{l}\text { Time lapsed from admission to } \\
\text { onset of labor }{ }^{c}(n=141)\end{array}$ & $24(10.25-48)$ \\
\hline
\end{tabular}

${ }^{a}$ For patients with severe preeclampsia and preeclampsia superimposed on chronic hypertension

${ }^{\text {b } F o r ~ p a t i e n t s ~ w i t h ~} \mathrm{DBP} \geq 110 \mathrm{mmHg}$

${ }^{C}$ For women with severe preeclampsia and preeclampsia superimposed on chronic hypertension
$25.73 \pm 4.8$ with the minimum of 15 years and maximum of 40 years. One hundred thirty-one (54.4\%) of them were rural dwellers (Table 1).

The study also assessed labor and early neonatal period complications that leads to possible neonatal death. According to the review, 20 of such complications were documented of which half were meconium aspiration.

\section{Patterns of preeclampsia management modalities}

The median time lapsed for the patients from onset of their symptoms to arrive to the hospital was $14 \mathrm{~h}$. A wide variability has been observed on the duration of time from admission to the onset of labor among patients diagnosed with severe preeclamptic and preeclampsia superimposed on chronic hypertension. Thus, the mean $( \pm \mathrm{SD})$ hour was $44.9( \pm 39.1)$ with the minimum of 1 and maximum $192 \mathrm{~h}$ (8 days) duration (Table 2 ).

Magnesium sulfate was the most frequently (69.3\%) used anticonvulsant medication used followed by diazepam (26.6\%). The most frequently used antihypertensive

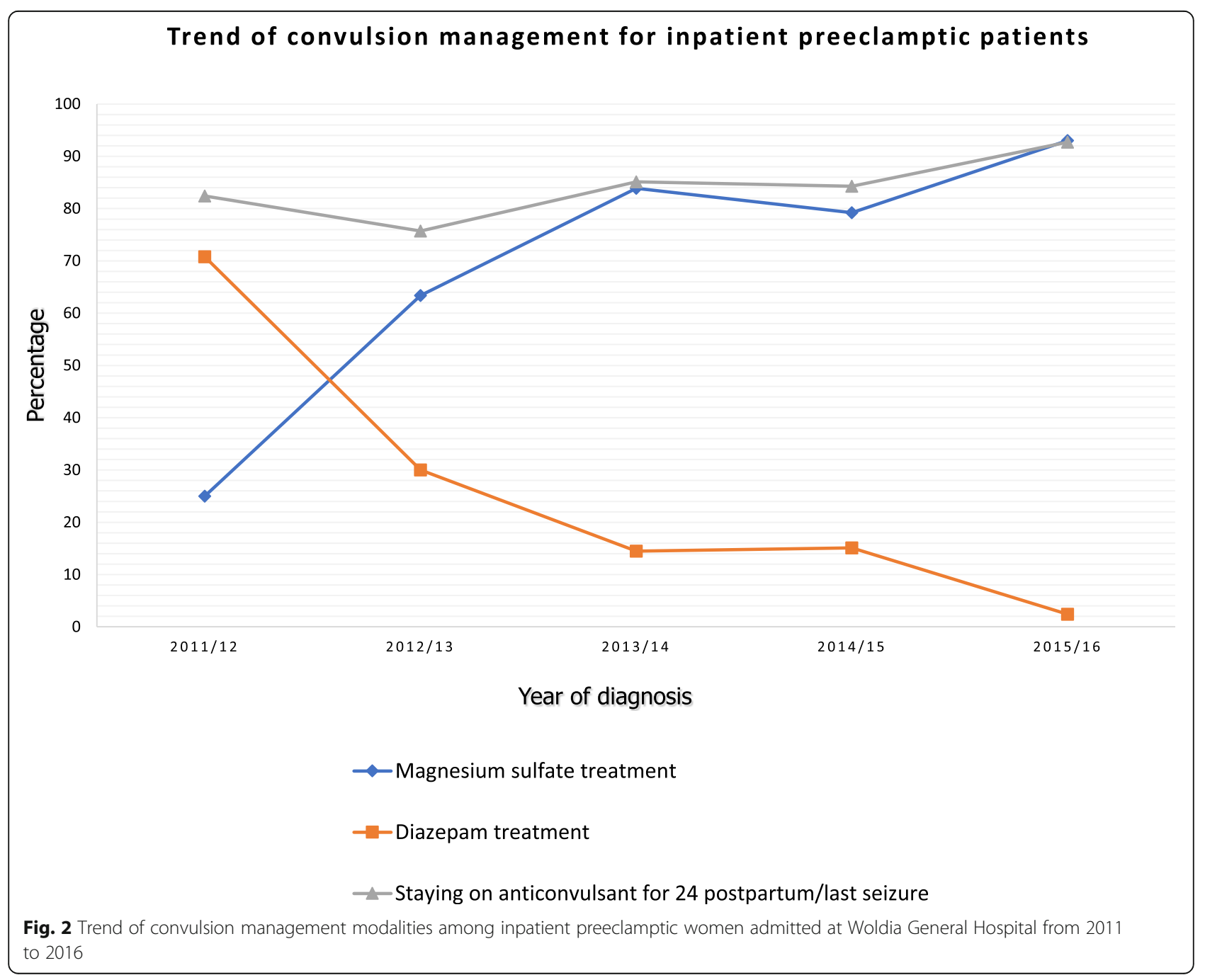


medications were hydralazine, methyldopa and nifedipine that were used 112, 111 and 54 times respectively. Anticonvulsant medication was given for 221 (91.7\%) during labor and its use continued for $24 \mathrm{~h}$ postpartum or since last convulsion for 177 (73.4\%) patients. Out of 239 patients, 148 (61.9\%) has commenced their labor spontaneously while it was intentionally induced for $91(38.1 \%)$ patients. Spontaneous vaginal delivery was the major route of delivery $114(47.5 \%)$ while $82(34.2 \%), 35(14.6 \%)$, and $9(3.75 \%)$ of patients managed by vacuum, caesarian section and forceps delivery respectively. Comparing the route of delivery with severity of the disease (classifid as mild or severe preeclampsia), the use of vacuum delivery and caesarean section were at a statistically higher frequency among severe preeclamptic women over their counter parts $\mathrm{x}^{2}(3, n=117)=2.398, p=0.013$, while no significant differences were observed in the frequency of spontaneous vaginal delivery $(p=0.613)$ (Fig. 2).

As shown in the Fig. 2, magnesium sulfate was the drug of choice to prevent convulsion in preeclamptic women. Its use increased from $25 \%$ in $2011 / 12$ to $93 \%$ in $2015 / 16(P<0.0005)$. Opposite to this, there was a decreasing trend for using diazepam from 54\% in 2011/ 12 to $1.6 \%$ in $2015 / 16(P<0.0005)$. In addition, extending the use of anticonvulsant medication $24 \mathrm{~h}$ postpartum or after the onset of last convulsion increased across the 5 years.

\section{Perinatal outcome}

The mean gestational age in weeks and days at birth was $37^{+6}\left( \pm 2^{+5}\right)$ and the minimum and the maximum value of 24 and 42 completed weeks respectively. The mean value for 1st and 5th minute APGAR score was $5.98( \pm 2.36)$ and $6.91( \pm 2.67)$ respectively. The mean value for birth weight was $2608.02( \pm 558.8)$ gram. Low birth weight was more frequently observed among severe preeclampsia than the mild one $(53.7 \%$ Vs 32\%) $p=0.001$. Out of 225 documents reviewed for fetal heart beat abnormalities, 24 (10.7\%) abnormal patterns were documented. Forty-Seven perinatal deaths were recorded across the 5-year period yielding a case specific perinatal mortality rate $197 / 1000$ births. Of this, 27(57.4\%) were documented as stillbirth and the rest $20(42.6 \%)$ were within the first week of their hospital stay. Perinatal death was higher (76.59\% Vs $23.4 \%$ ) among offspring from severe preeclampsia patients than their mild counterparts $(p=0.01)$ (Fig. 3).

Using logistic regression, important independent variables were checked for their possible association both in bivariable and multivariable logistic regression with a $p$ value less than 0.05 . Three variables were significantly associated with perinatal death both in bivariable and multivariable logistic regression; namely intrapartum fetal heart rate pattern, manifestations of end organ involvement, and 5th minute APGAR score. It was observed that the odds of perinatal death among those with manifestation of end-organ involvements were 4

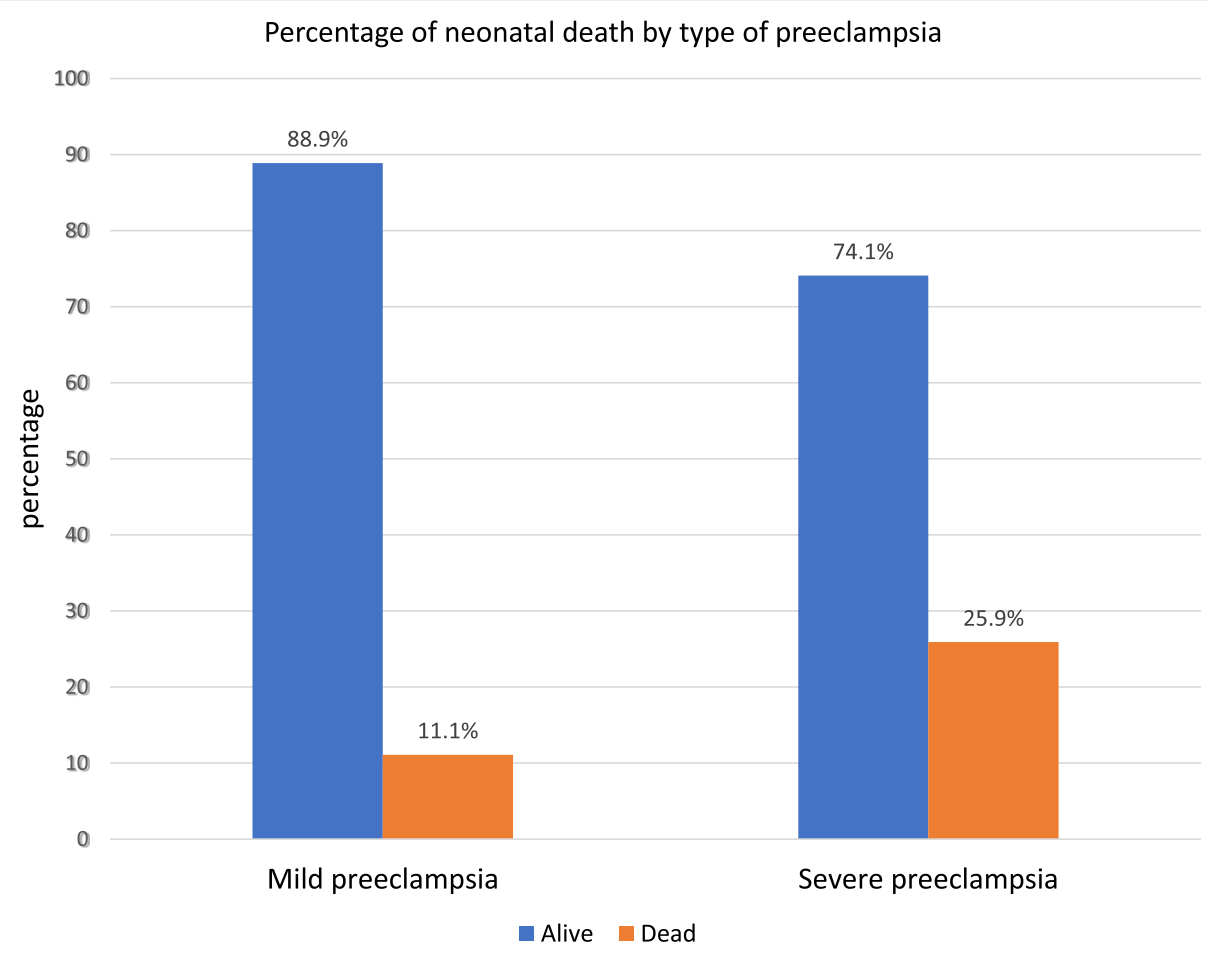

Fig. 3 Percentage of perinatal death versus type preeclampsia at Woldia General Hospital from 2011 to 2016 
times $(\mathrm{AOR}=4.40495 \% \mathrm{CI}(1.219-6.370))$ higher than their counterparts (Table 3 ).

We found that a group of conditions operationalized as 'labor and early neonatal complications' increased the odds of perinatal death nearly by 5 -fold. However, this variable is an independent cause of perinatal death even in the absence of preeclampsia. Therefore, the multivariable logistic regression was repeated in which 'labor and early neonatal complications' and other independent variables were entered into the regression model with separate blocks. From the final analysis, it was found that the diastolic blood pressure measurement and 5th minute APGAR score were associated with perinatal death.
Accordingly, the odds of perinatal death was nearly 3times $(\mathrm{AOR}=2.824 ; 95 \% \mathrm{CI}(1.154-6.038))$ higher among women who had diastolic blood pressures greater than $110 \mathrm{mmHg}$ taken at admission compared to those who had below $110 \mathrm{mmHg}$. Neonates whose 5-min APGAR score was between 0 to 3 has a 5 -fold (AOR $=5.046$; $95 \%$ CI (1.856-8.235)) greater risk of death than neonates whose 5-min APGAR was between 7 and 10.

\section{Discussion}

The time-lapsed from onset of symptoms to the patient reaching health care support is a combined reflection of patient's health-care seeking behavior, access to health

Table 3 A bivariable and multivariable logistic regression analysis result testing for factors associated with perinatal outcome (death/ alive) among neonates delivered from preeclamptic women from 2011 to 2016 (before the effect of labor and early neonatal complication controlled

\begin{tabular}{|c|c|c|c|c|c|}
\hline Variable & & COR, $(95 \% \mathrm{Cl})$ & $p$-value & $\mathrm{AOR},(95 \% \mathrm{Cl})$ & $p$ value \\
\hline \multirow[t]{2}{*}{ Diastolic Blood pressure measurement $(n=231)$} & Less than $110 \mathrm{mmHg}$ & 1 & 0.009 & 1 & 0.335 \\
\hline & $\geq 110 \mathrm{mmHg}$ & $3.688(1.257-4.863)$ & & $1.606(0.034-3.177)$ & \\
\hline \multirow[t]{2}{*}{ Manifestation of end-organ involvement } & Yes & $4.667(1.332-8.001)$ & 0.012 & $4.404(1.219-6.370)$ & $0.035^{*}$ \\
\hline & No & 1 & & 1 & \\
\hline \multirow[t]{2}{*}{ Gestational age at birth } & $<37$ completed weeks & $2.547(1.073-4.021)$ & 0.030 & $1.105(0.098-2.111)$ & 0.315 \\
\hline & $\geq 37$ completed weeks & 1 & & 1 & \\
\hline \multirow{2}{*}{$\begin{array}{l}\text { Time lapsed from admission to initiation } \\
\text { of } \mathrm{MgSO}_{4}{ }^{\mathrm{b}}(n=139)\end{array}$} & Less than $1 \mathrm{~h}$ & 1 & & 1 & \\
\hline & More than $1 \mathrm{~h}$ & $1.254(0.343-2.164)$ & 0.751 & $2.780(0.558-5.002)$ & 0.427 \\
\hline \multirow{4}{*}{$\begin{array}{l}\text { Time lapsed from admission to initiation } \\
\text { of antihypertensives }{ }^{c}(n=101)\end{array}$} & Less than $17 \mathrm{~min}$ & $2.962(0.331-5.593)$ & 0.669 & $3.636(0.231-7.014)$ & 0.125 \\
\hline & $17-30 \mathrm{~min}$ & $3.436(0.479-6.392)$ & 0.397 & & \\
\hline & $30 \mathrm{~min}$ to $1 \mathrm{~h}$ & $2.331(0.195-4.467)$ & 0.931 & & \\
\hline & More than or equal to $1 \mathrm{~h}$ & 1 & & 1 & \\
\hline \multirow{2}{*}{$\begin{array}{l}\text { Time lapsed from admission to onset } \\
\text { of labor }^{d}(n=141)\end{array}$} & Less than $35 \mathrm{~h}$ & 1 & & 1 & 0.412 \\
\hline & More than or equal to $35 \mathrm{~h}$ & $1.353(0.235-2.452)$ & 0.644 & $1.951(0.896-3.006)$ & \\
\hline \multirow[t]{2}{*}{ Qualitative proteinuria ( $n=223$ ) } & Mild proteinuria & 1 & 0.776 & 1 & 0.623 \\
\hline & Marked proteinuria & $1.395(0.547-2.243)$ & & $1.159(0.113-2.091)$ & \\
\hline \multirow{2}{*}{$\begin{array}{l}\mathrm{MgSO}_{4} \text { continues } 24 \mathrm{~h} \text { after delivery } \\
(n=210)\end{array}$} & Yes & 1 & 0.024 & 1 & \\
\hline & No & $3.132(1.048-4.168)$ & & $4.069(0.896-6.347)$ & 0.221 \\
\hline \multirow[t]{2}{*}{ Intrapartum Fetal heart rate $(n=225)$} & Normal & 1 & 0.014 & 1 & 0.112 \\
\hline & Some abnormal records & $6.328(2.069-10.587)$ & & $4.846(0.667-9.025)$ & \\
\hline \multirow[t]{2}{*}{ Onset of labor } & Spontaneous & 1 & & 1 & 0.119 \\
\hline & Induced & $5.580(2.237-8.923)$ & & $7.477(0.633-14.322)$ & \\
\hline \multirow{2}{*}{$\begin{array}{l}\text { Labor and early neonatal complications } \\
(n=239)\end{array}$} & Yes & $3.454(1.321-5.588)$ & 0.006 & $4.616(1.365-7.867)$ & $0.017^{*}$ \\
\hline & No & 1 & & 1 & \\
\hline \multirow[t]{3}{*}{ Fifth minute APGAR score ${ }^{a}(n=214)$} & $0-3$ & $13.962(6.499-21.426)$ & 0.011 & $5.046(1.856-8.235)$ & $0.0005^{*}$ \\
\hline & $4-6$ & $7.645(2.629-12.660)$ & 0.003 & $3.112(1.223-5.001)$ & $0.021^{*}$ \\
\hline & $7-10$ & 1 & & 1 & \\
\hline
\end{tabular}

Key: COR: Cruds odd ratio

*show association with $\mathrm{p}$ value less than 0.05

a analysis was done after excluding stillbirths

${ }^{b}$ For patients with severe preeclampsia and preeclampsia superimposed on chronic hypertension

${ }^{\mathrm{C}}$ For patients with DBP $>110 \mathrm{mmHg}$

${ }^{d}$ For women with severe preeclampsia and preeclampsia superimposed on chronic hypertension 
care, infrastructure and transportation. Regarding the management modalities used, we believed that in addition to comparing this study finding with others', discussing our findings with national guideline and protocols will help to identify the magnitude of management gap.

In previous research, the rate of perinatal mortality among those mothers with preeclampsia ranged from 47/ 1000 to 416/1000 live births [5-8]. The perinatal mortality rate recorded in our study (197/1000 live births) was within this range but slightly higher than two studies with rates of 120/1000 and 160/1000 deaths per live births [2, 12]. Differences in death rates might arise from difference in the gestational age cut off points used among studies, the type of hypertensive disorders included, and service-delivery capacity of the hospitals where the patients were managed.

Similar to other studies, in this sample, $47.5 \%$ of all preeclamptic women had vaginal births $[14,15]$. Vaginal delivery is also the preferred route of delivery for preeclamptic women according to the Ethiopian Minister of Health protocol [16]. Rates of labor induction vary a great deal across studies. Similar to a rural hospital in Western Tanzania, in this study labor was induced in $38.1 \%$ of the patients [17]. In contrast, $47.9 \%$ of patients were induced at the Mettu Karl Referral Hospital [12] and 23.4\% in governmental hospitals of Addis Ababa [14]. The possible explanation for this difference could be the fact that labor induction has a variety of chief indications other than preeclampsia.

In three studies, usage of magnesium sulfate in preeclamptic women to prevent seizures ranged from 74.1 to $100 \%[12,14,17]$ similar to our finding of $(91.7 \%)$. In addition to this, this study revealed that anti-convulsant medication was continued for $24 \mathrm{~h}$ postpartum for 177 (73.4\%) patients. Although this finding was consistent with the aforementioned studies conducted in resource-limited areas, it was lagged behind to achieve the Ethiopian Ministry of Health management protocol which recommends the use of magnesium sulfate for all preeclamptic woman during labor. It's also recommended that magnesium sulfate treatment should continue for $24 \mathrm{~h}$ postpartum [16, 18]. Unavailability of the drug or failure either to give the drug or to document could be the possible explanation for this discrepancy.

The median duration for women with severe preeclampsia between admission and labor was $24 \mathrm{~h}$ (IQR 10.25-48) which was shorter than other study conducted among patients with severe preeclampsia and eclampsia [17]. Shorter hospital stay for severe preeclamptic women at term was stated as a supported management option in studies and management protocols $[16,19]$.

Similar to our finding, other studies in low-resource settings reported more stillbirths than deaths at early neonatal period $[15,20,21]$. We found that women who had diastolic blood pressures above $110 \mathrm{mmHg}$ had a 2-fold increased chance of perinatal death compared to those with lower diastolic blood pressures. Similar association has been also detected in other studies [22, 23].

\section{Limitation}

As a limitation, this study didn't assess the effect of steroid drugs on perinatal death among preeclamptic women as only few numbers of cases received the treatment.

\section{Conclusion}

In conclusion, perinatal death was high among inpatient preeclamptic women who gave birth at Woldia General Hospital. The trend of using magnesium sulfate as an anticonvulsant increased through the 5-year period. However, there was a gap to extend its use up to $24 \mathrm{~h}$ postpartum or since the last convulsion as per the national protocol. From our analysis, diastolic blood pressure and 5th minute Apgar score were found associated with perinatal death. Authors recommended that future large-scale health service auditing and impact assessment studies in such resource limitedareas might serve as an input for policymakers to improve the quality of clinical care and to decrease mortality rates.

\section{Abbreviations}

APGAR: Appearance, Pulse, Grimace, Activity, Respiration; HDP: hypertensive disorders of pregnancy; Hgb: Hemoglobin

\section{Acknowledgments \\ We would like to thank Woldia University for the grant allocated to conduct this study. We also extend our deepest gratitude to Woldia General Hospital Administrative bodies and staffs working at the hospital archive. Last but not the least, we would like to extend our gratefulness and heartfelt thanks to all our colleagues who gave us their unduly support, critical comments and helpful information.}

\section{Authors' contributions}

KG and ML conceptualized the study, its design, analysis, interpretation, wrote the manuscript. YA, MM and MW participated on the design, analysis of study findings and interpretation of its result. All the authors read and approved the final manuscript.

Funding

This study was funded by Woldia University with grant number WURCSVP/209/ 2017. The funding body didn't have any role in the design of the study and collection, analysis, and interpretation of data and in writing the manuscript.

\section{Availability of data and materials}

The datasets used for analysis during the current study are available from the corresponding author on reasonable request.

\section{Ethics approval and consent to participate}

Ethical clearance was obtained from institutional review board of Woldia University. Permission was also obtained from the hospital administrative office to retrieve patients' data from their archive. Data collectors took training how to use patients' information confidentially. Since data were extracted by document review, written or oral consent from patients was not applicable.

\section{Consent for publication}

Not applicable.

Competing interests

The authors declare that they have no competing interests. 


\section{Author details}

${ }^{1}$ College of Health Science, Woldia University, Woldia, Ethiopia. ${ }^{2}$ College of Health Science, Axum University, Axum, Ethiopia. ${ }^{3}$ College of Health Science, Debre Berhan University, Debre Berhan, Ethiopia.

Received: 20 December 2019 Accepted: 29 March 2020

Published online: 09 April 2020

\section{References}

1. Central Statistical Agency Addis Ababa Ethiopia, ICF International Calverton Maryland, USA. Ethiopia Demographic and Health Survey 2011. In: CSA, editor. . Addis Ababa and Calverton; 2012.

2. Lawn JE, Blencowe $H$, Waiswa P. Stillbirths: rates, risk factors, and acceleration towards 2030. Lancet. 2016;387(6):17.

3. Vogel JP, Souza JP, Mori R. Maternal complications and perinatal mortality: findings of the World Health Organization multicountry survey on maternal and newborn health. BJOG. 2014;121(1):13.

4. Lawn JE, Blencowe H, Oza S. Every newborn: progress, priorities, and potential beyond survival. Lancet. 2014;384(12):17.

5. Singhal SR, Deepika A, Nanda S. Maternal and perinatan outcome in severe preeclampsia and eclampsia. JSAFOG. 2009;1(3):8.

6. Vidhyadhar BB, Purushottam AG, Aditi SM. Maternal and foetal outcome in pregnancy induced hypertension: a study from rural tertiary care teaching hospital in India. Int J Biomed Res. 2011;2

7. Tuffnell DJ, Jankowicz D, Lindow SW, Lyons G, Mason GC, Russell IF. Outcome of severe preeclampsia/ eclampsia. J Obstet Gynecol. 2005;112:6

8. Al Inizi ST, Sharara H, Ahmed B. Eclampsia in Quatar: maternal and fetal outcomes, possible preventive measures. Mid East J Emerg Med. 2005;5:6.

9. Knight M. Eclampsia in the United Kingdom 2005. BJOG. 2007;114(9):8.

10. Onuh $\mathrm{SO}$, Aisien $\mathrm{AO}$. Maternal and fetal outcome in eclamptic patients in Benin City, Nigeria. J Obstet Gynaecol. 2004;24(7):8.

11. Wolde Z, Segni H, Woldie M. Hpertensive disorders of pregnancy in Jimma University specialized hospital. Ethiop J Health Sci. 2010;21:147-54.

12. Seyom E, Abera M, Tesfaye M, Fentahun N. Maternal and fetal outcome of pregnancy related hypertension in Mettu Karl referral hospital, Ethiopia. J Ovarian Res. 2013;8.

13. Pannu D, Das B, Hazari P, Shilpa. Maternal and perinatal outcome in eclampsia and factors affecting the outcome: a study in North Indian population. Int J Reprod Contracep Obstet Gynecol. 2010;3:347-51.

14. Wagnew M, Dessalegn M, Worku A, Nyagero J. Trends of preeclampsia/ eclampsia and maternal and neonatal outcomes among women delivering in Addis Ababa selected government hospitals, Ethiopia: a retrospective cross-sectional study. Pan Afr Med J. 2016;25(2):12.

15. Nazarius PK, Tumwesigye M, Wandabwa J, Wamuyu-Maina G, Bimenya GS, Okong P. Adverse neonatal outcomes in women with preeclampsia in Mulago Hospital, Kampala, Uganda: a cross-sectional study. Pan Africa Med J. 2009;17.

16. Health Federal Democratic Republic of Ethiopia Ministry of Management protocol on selected obstetrics topics. Pregnancy Induced Hypertension 2010:22.

17. Mooij R, Lugumila J, Mwashambwa MY, Mwampagatwa IH, van Dillen J, Stekelenburg J. Characteristics and outcomes of patients with eclampsia and severe pre-eclampsia in a rural hospital in Western Tanzania: a retrospective medical record study. BMC Pregnancy Childbirth. 2012;15.

18. Sibai BM. Magnesium sulfate prophylaxis in preeclampsia: Lessons learned from recent trials. Am J Obstet Gynecol. 2004;190.

19. Barber D, Xing G, Towner D. Expectant management of severe eclampsia between 24-32 weeks gestation: a ten-year review: The 29th Annual Meeting of the Society for Maternal-Fetal Medicine; 2009.

20. Endeshaw G, Berhan Y. Perinatal Outcome in Women with Hypertensive Disorders of Pregnancy: a retrospective cohort study. Int Scholarly Res Notices. 2013;2015:8.

21. Ananth CV, Basso O. Impact of pregnancy-induced hypertension on stillbirth and neonatal mortality in first and higher order births: a population- based study. NIH Public Access. 2010;21:118-23.

22. Judy A, Chao L, Girsen A, O'Malley K, Lyell D, Blumenfeld Y, Butwick A, El-Sayed Y. Maternal characteristics and neonatal outcomes in women with eclampsia versus severe preeclampsia. Am J Obstet Gynecol. 2014;192(1):S188-90.

23. Thangaratinam S, Datta A, Ismail KMK, Khan KS. What is the accuracy of blood pressure in predicting complications in pre-eclampsia? Arch Dis Child Fetal Neonatal Ed. 2011;96(1):9.

\section{Publisher's Note}

Springer Nature remains neutral with regard to jurisdictional claims in published maps and institutional affiliations.

\section{Ready to submit your research? Choose BMC and benefit from:}

- fast, convenient online submission

- thorough peer review by experienced researchers in your field

- rapid publication on acceptance

- support for research data, including large and complex data types

- gold Open Access which fosters wider collaboration and increased citations

- maximum visibility for your research: over $100 \mathrm{M}$ website views per year

At BMC, research is always in progress.

Learn more biomedcentral.com/submissions 